\title{
The regulation of mineral absorption in the gastrointestinal tract
}

\author{
J. J. Powell*†, R. Jugdaohsingh and R. P. H. Thompson \\ Gastrointestinal Laboratory, The Rayne Institute, St Thomas' Hospital, London SE1 7EH, UK
}

\begin{abstract}
The absorption of metal ions in the mammalian single-stomached gut is fortunately highly selective, and both luminal and tissue regulation occur. Initially, assimilation of metal ions in an available form is facilitated by the intestinal secretions, chiefly soluble mucus (mucin) that retards hydrolysis of ions such as $\mathrm{Cu}, \mathrm{Fe}$ and $\mathrm{Zn}$. Metal ions then bind and traverse the mucosallyadherent mucus layer with an efficiency $\mathrm{M}^{+}>\mathrm{M}^{2+}>\mathrm{M}^{3+}$. At the mucosa $\mathrm{Fe}^{3+}$ is probably uniquely reduced to $\mathrm{Fe}^{2+}$, and all divalent cations (including $\mathrm{Fe}^{2+}$ ) are transported by a membrane protein (such as divalent cation transporter 1) into the cell. This minimizes absorption of toxic trivalent metals (e.g. $\mathrm{Al}^{3+}$ ). Intracellular metal-binding molecules (such as mobilferrin) may be present at the intracellular side of the apical membrane, anchored to a transmembrane protein such as an integrin complex. This mobilferrin would receive the metal ion from divalent cation transporter 1 and, with part of the integrin molecule, transport the metal to the cytosol for safe sequestration in a larger complex such as ferritin or 'paraferritin'. $\beta_{2}$-Microglobulin and HFE (previously termed human leucocyte antigen $\mathrm{H}$ ) may be involved in stabilizing metal mobilferrin-integrin to form this latter complex. Finally, a systemic metal-binding protein such as transferrin may enter the antiluminal (basolateral) side of the cell for binding of the sequestered metal ion and delivery to the circulation. Regulatory proteins, such as HFE, may determine the degree of ion transport from intestinal cells to the circulation. Gradients in $\mathrm{pH}$ and perhaps $\mathrm{pCa}$ or even pNa could allow the switching of ions between the different transporters throughout this mechanism.
\end{abstract}

Metal ion absorption: Gastrointestinal tract: Aluminium: Iron: Zinc

The absorption of metal ions in the mammalian singlestomached gut is fortunately highly selective. Thus, essential dietary cations, such as $\mathrm{Cu}, \mathrm{Zn}$ and Fe are generally absorbed 10-100-fold more efficiently than toxic dietary ions such as Al. In previous reviews (Powell et al. 1994; Whitehead et al. 1996) we have discussed the relationship between the anatomy, biochemistry and physiology of the gastrointestinal lumen and the regulation of mineral absorption. Here we concentrate on the absorptive role of the most important luminal metal-binding species, i.e. mucus, and explore mechanisms for the subsequent transmucosal uptake of metal ions.

\section{Background}

Ingested metals may be considered in two categories: those soluble throughout the potential $\mathrm{pH}$ range of the gastrointestinal lumen (approximately $\mathrm{pH} 1-8$ ), such as $\mathrm{Na}, \mathrm{Mg}$ and $\mathrm{Ca}$, and those susceptible to hydroxy-polymerization, such as $\mathrm{Al}, \mathrm{Cu}, \mathrm{Fe}, \mathrm{Mn}$ and $\mathrm{Zn}$. This latter group, termed 'hydrolytic metals', are acid-soluble, but as the $\mathrm{pH}$ is raised in the absence of soluble binding ligands, they readily form insoluble hydroxide precipitates. This sometimes led, incorrectly, to the belief that hydrolytic metal ions were absorbed from the 'soluble' acidic gastric environment and not from the 'insoluble' peri-neutral intestinal environment (Stewart, 1989). In fact, the stomach has little absorptive capacity, with a small surface area and a thick protective layer of $\mathrm{pH}$-buffered gelatinous mucus (Fig. 1), and is remarkably impermeable to the absorption of nutrients, including metal ions (Whitehead et al. 1997). Nonetheless, the stomach plays an important role in the 'preparation' of ingested metals for later absorption. A marked reduction in gastric acid output (hypochlorhydria) may be ineffective in dissociating a metal ion from its ingested matrix (e.g. Fe in food (Champagne, 1989) or Al in an antacid), leading to a reduced luminal concentration of solubilized and potentially-available metal. Furthermore,

*Corresponding author: Dr Jonathan J. Powell, fax +1530753 3545, email jonpowel@ ucdavis.edu

$\nmid$ Present address: Department of Immunology, TB192, Internal Medicine, University of California at Davis, Davis, CA 95616, USA 
(A)

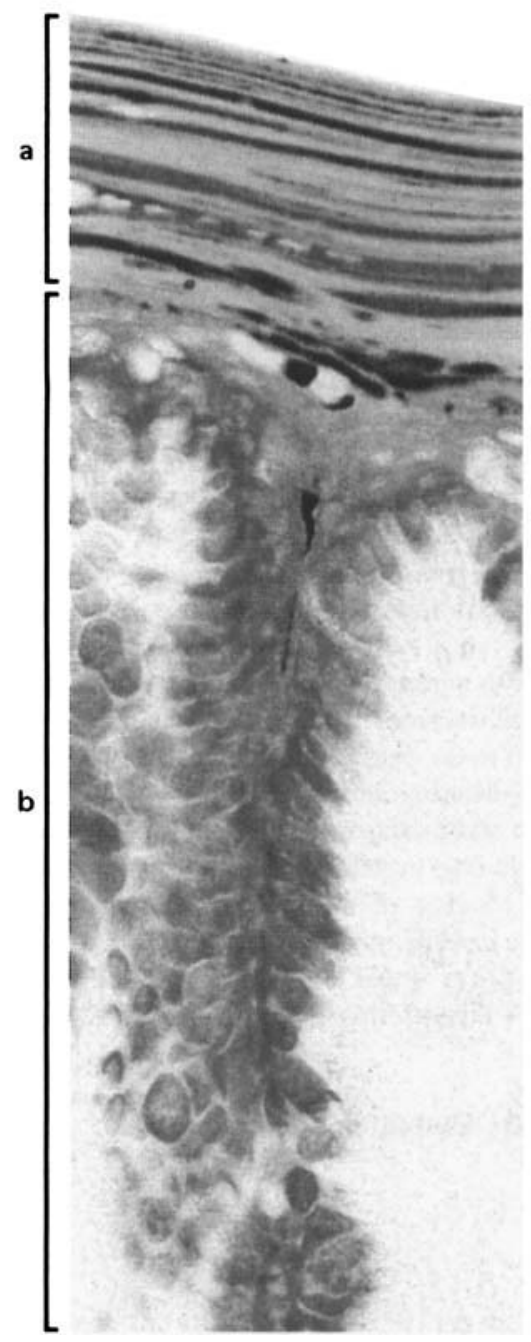

(B)

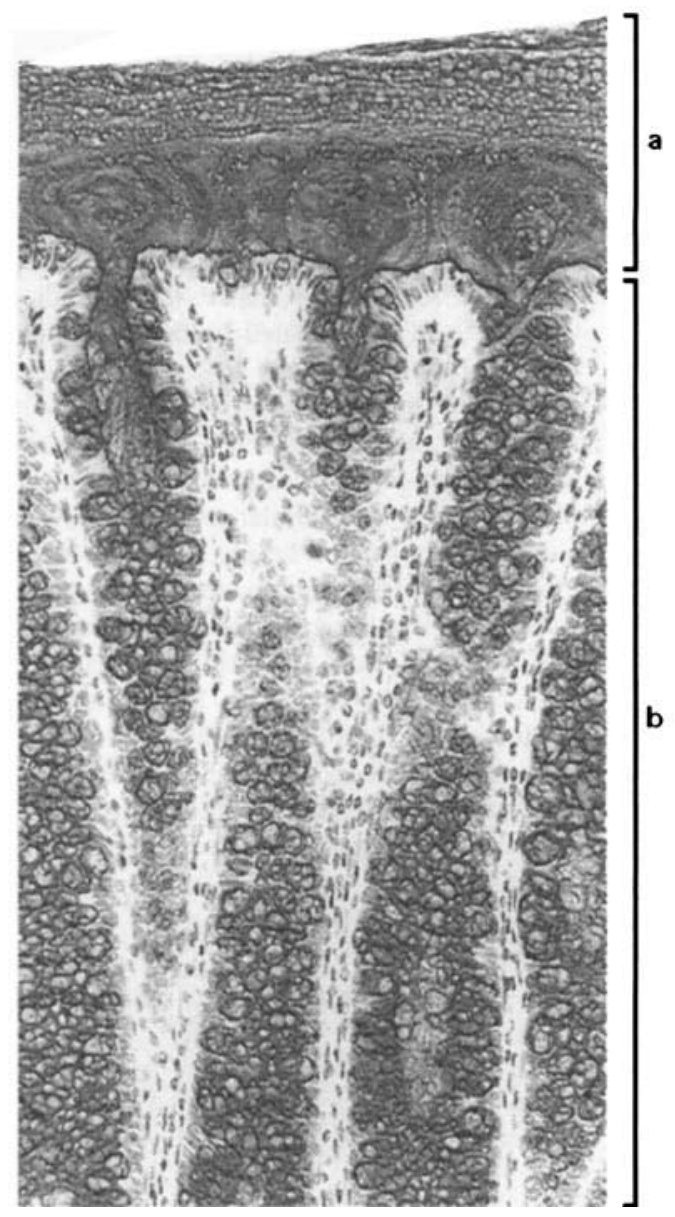

Fig. 1. (A) A distinctly-structured, laminated, mucus layer (a) overlies the mammalian gastrointestinal tract (b; showing surface pyloric mucosal cells of the human stomach). Glycoprotein from pyloric gland cells was stained with paradoxical concanavalin A (dark bands in (a)), while glycoprotein of surface mucus cells was stained with the galactose oxidase-cold thionine reaction (light bands in (a) and dark areas in (b)). (B) The ubiquitous nature of sialic acid in the mucus layer of the human intestine (colon) is shown (dark areas). This section was stained with a periodic acid-sodium borohydride-potassium hydroxide-periodic acid Schiffs reagent sequence. Both the mucus layer (a) and the goblet cells of the mucosa (b) stain red (dark areas), indicating the presence of 8-O-acetyl-neuraminic acid, a histochemical marker of the large intestine. Regular whorl formation in the mucus layer above crypt openings suggests that mucus is expelled from goblet cells in a controlled fashion into the mucus layer. (Micrographs provided by Professor Katsuyama's group, Shinshu University, Japan.)

secreted gastric juice, which mixes with the luminal contents, contains solubilized mucin (once termed 'gastroferrin', see p. 148) that helps hydrolytic metals to remain soluble at near-neutral $\mathrm{pH}$ such as that occurring with transient gastric acid buffering by food or following gastric emptying into the small bowel (Powell et al. 1994). Indeed, it is the small intestine, which also secretes numerous endogenous ligands and again most notably mucin, that is the predominant site of mineral absorption (Whitehead et al. 1996).

\section{Luminal mucin: gastroferrin}

The large glycoprotein mucin is secreted throughout the gastrointestinal tract which provides both the mucosallyadherent gelatinous layer (mucus, see p. 150) and a soluble luminal form (Hunter et al. 1989). Much of the soluble form occurs as a degradation product of the mucus layer, and its role in metal binding has been well demonstrated (Crowther, 1982; Crowther \& Marriott, 1984; Conrad et al. 1991). Between 1963 and 1973 a number of authors demonstrated an Fe-binding glycoprotein in human gastric juice that was 
termed 'gastroferrin' (Davis et al. 1969; Rudzki et al. 1973; Rudzki \& Deller, 1973). This isolated glycoprotein maintained $\mathrm{Fe}^{3+}$ in solution at neutral $\mathrm{pH}$, suggesting that it played a role in facilitating intestinal $\mathrm{Fe}$ absorption, although it was present in gastric juice at similar levels in healthy individuals and in those with Fe-related disorders (Rudzki et al. 1973). Significant characterization of gastroferrin was carried out by Rudzki et al. (1973) and Rudzki \& Deller (1973), who demonstrated its carbohydrate and amino acid content, homology with blood-group antigens, and interactions with metal ions. These findings, in particular the blood-group antigen activity, identify gastroferrin as gastric mucin, and indeed, information on the role of gastroferrin in promoting intestinal $\mathrm{Fe}$ absorption is identical to that from recent work with intestinal mucin and $\mathrm{Fe}$ (Conrad et al. 1991; Fig. 2). Interestingly, much of the $\mathrm{Fe}$ is bound non-stoichiometrically by mucin (Rudzki et al. 1973), with the glycoprotein stabilizing colloidal poly-hydroxy ion cores and preventing their further polymerization (Rudzki et al. 1973; Fig. 2). In vitro,

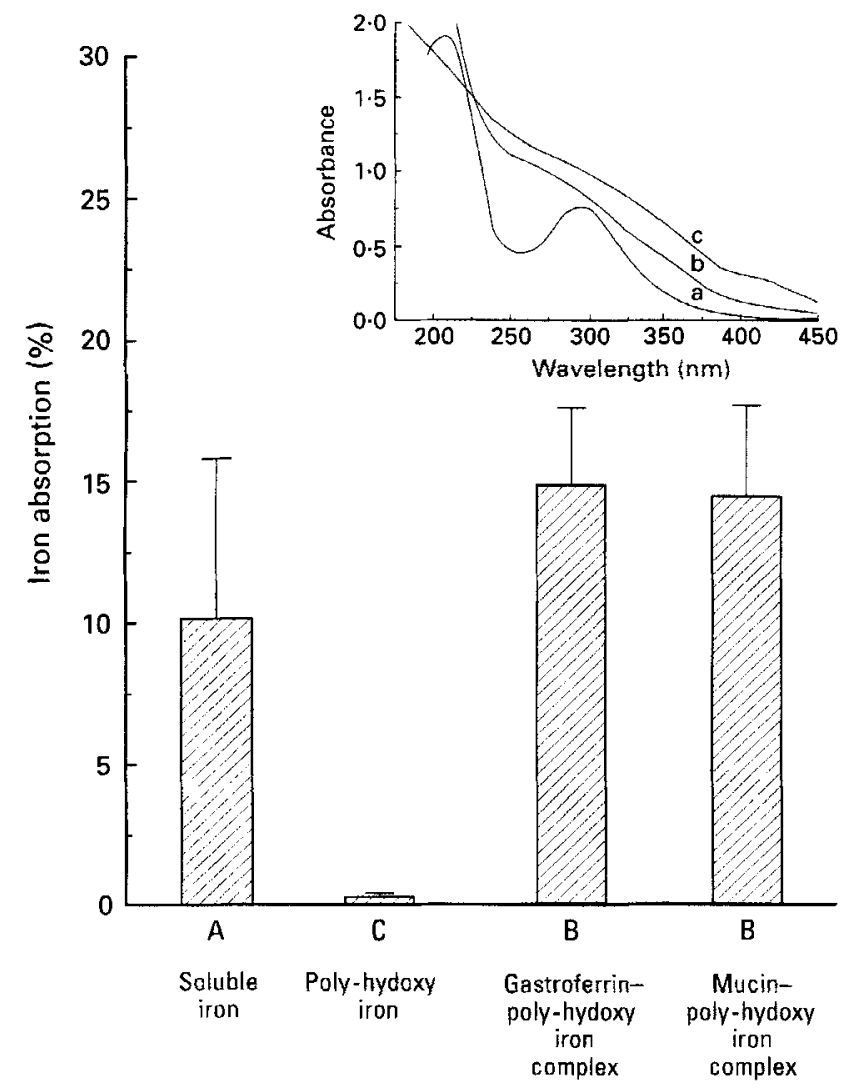

Fig. 2. A solution of ferric chloride at $\mathrm{pH} 2$ has a characteristic u.v. spectrum ( $a$ in inset) and, although unphysiologically acidic for the small intestine, it is fully soluble, allowing some absorption of iron when directly introduced to the bowel (A). In contrast, at neutral $\mathrm{pH}$, the solution forms poly-hydoxy iron species that yield a lightscattering spectrum (c in inset) and, although now at physiological $\mathrm{pH}$, are unavailable for absorption in the bowel (C). However, iron bound to gastroferrin (or mucin) maintains its characteristic polyhydroxy spectrum at neutral $\mathrm{pH}$ (b in inset) but is also available for absorption in the bowel (B). Values are means and standard deviations represented by vertical bars. (Data combined from Rudzki et al. 1973 and Conrad et al. 1991, with permission.) these aggregates varied in size from 2 to $20 \mathrm{~nm}$ diameters (Rudzki et al. 1973) and, by comparison with the similar poly-hydroxyferric fructose system (Bates et al. 1972; Bates, 1973), are expected to be easily dissociable, thus maintaining $\mathrm{Fe}$ in a readily-available form. Indeed, instillation of the $\mathrm{Fe}(\mathrm{OH})_{3}$-mucin complex into the rat gastrointestinal tract yields effective absorption that is clearly not seen with $\mathrm{Fe}(\mathrm{OH})_{3}$ alone or even with 'uncomplexed' $\mathrm{Fe}(\mathrm{OH})_{3}+$ mucin (Rudzki et al. 1973; Conrad et al. 1991; Fig. 2). Soluble mucins from the stomach and intestinal tract behave similarly, not only in their Fe-binding capacity, but also in their binding to other metals. Combining data from a number of papers (Rudzki et al. 1973; Crowther, 1982; Crowther \& Marriott, 1984; Conrad et al. 1991) suggests that the affinity of gastrointestinal mucin for metals follows the pattern: $\mathrm{Fe}^{3+}>\mathrm{Al}^{3+}, \mathrm{Cr}^{3+}>\mathrm{Pb}^{2+}>\mathrm{Zn}^{2+}>\mathrm{Co}^{2+}>\mathrm{Ca}^{2+}>\mathrm{Na}^{+}, \mathrm{Cs}^{+}$(i.e. $\left.\mathrm{M}^{3+}>\mathrm{M}^{2+}>\mathrm{M}^{+}\right)$. Although initially this appears to hold few surprises, given the nature of metal binding to polyelectrolytes, metal-mucin interactions are not so simple. First, although poly-hydroxy $\mathrm{Fe}$ clearly interacts with mucin, it also appears that monomeric ionic Fe presented to mucin by low-molecular-mass ligands also binds to mucin (Conrad et al. 1991). Indeed, we have shown that potential ligands of low molecular mass are secreted in the gastrointestinal fluids (such as lactate, pyruvate, histidine and bicarbonate; Powell et al. 1990; Whitehead et al. 1996); these may transiently stabilize metal hydroxy-polymerization, and could allow stoichiometric donation to mucin.

Second, there may be more than one binding site on mucin, since the molecule contains both sulfated groups (sulfated mucins) and carboxylate groups (sialomucins; Rhodes, 1989). Metal ions are anticipated to bind preferentially to one site or another, with covalent-type binding by 'soft' metals (e.g. $\mathrm{Pb}^{2+}, \mathrm{Cd}^{2+}$ ) to sulfated groups and ionictype binding by 'hard' metals (e.g. $\mathrm{Al}^{3+}, \mathrm{Fe}^{3+}$ ) to carboxylate groups. However, some previously unpublished findings (J Quarterman, unpublished results; Fig. 3) suggest that $\mathrm{Zn}$ has two $\mathrm{pH}$-dependent binding sites on mucin. Such

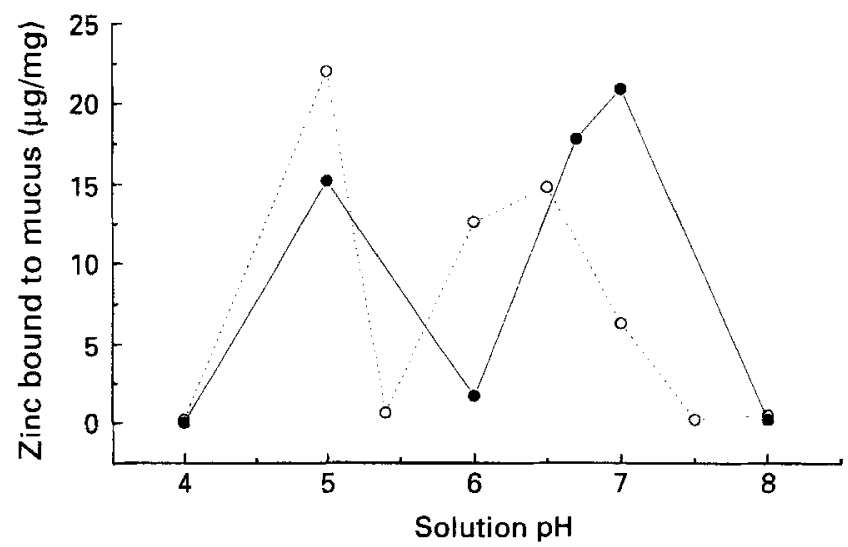

Fig. 3. Dialysis results showing zinc binding to isolated porcine mucus with increasing $\mathrm{pH}(O)$ and decreasing $\mathrm{pH}(O)$. The data suggest that two $\mathrm{pH}$-sensitive binding sites exist on mucus for zinc (and possibly other metal ions), and that a $\mathrm{pH}$ of 5.5-6 may facilitate dissociation of the metal-mucus complex. (Data provided by Dr J. Quarterman, Aberdeen, UK; formerly of The Rowett Institute, Aberdeen.) 
observations on the complex interaction between metal ions and mucins make it difficult to interpret competition studies between different metals for mucin, or between mucin and different ligands for metals. For example, Rudzki et al. (1973) showed that in the presence of a tenfold molar excess of ascorbate or citrate Fe would not bind to mucin. However, with identical concentrations mucin-bound $\mathrm{Fe}$ could not be released by citrate or ascorbate (Rudzki et al. 1973). Thermodynamic measurements require the reverse reaction to equilibrate similarly to the forward reaction, but kinetic effects, particularly marked in colloidal and/or polyelectrolyte-containing systems, often preclude the simple generation of thermodynamic data. Hence, the proposed $\mathrm{Fe}$-mucin dissociation constant of $10^{-4} \mathrm{M}$ (Conrad et al. 1991) may not be reliable or even relevant in vivo during transit of the (nonequilibrium) gastrointestinal tract. Nevertheless, we have demonstrated in situ the marked luminal interaction of ingested metal ( $\mathrm{Al}$ ) and intestinal mucin (Powell, 1994; Whitehead et al. 1995; Fig. 4), which is favoured by the large concentration of mucin in the intestinal lumen and its overall high capacity for metal ions and/or their polyhydroxy species. Further work will be required to delineate the exact in vivo nature of the soluble mucin-metal interactions, the influence of endogenous or dietary ligands, and how mucin promotes the availability of dietary metals to the mucosally-adherent mucus layer for the next phase of absorption.

\section{Mucosally-adherent mucus layer}

Some remarkable work from Katsuyama's group (Ota \& Katsuyama, 1992; Shimizu et al. 1996) has recently demonstrated the in situ structure of the gastrointestinal mucosallyadherent mucus layer. This leaves little doubt that not only is this a continuous thick layer in constant contact with the mucosa, but it is an alternating laminated array of distinct glycoproteins, rather than an amorphous gel (Fig. 1). Within this layer is a pH gradient influenced only at its surface by the luminal $\mathrm{pH}$ and otherwise controlled by the mucosal microclimate $\mathrm{pH}$ at the tissue-mucus interface (Powell et al. 1994). This again allows order (acid-base control) in the mucus layer, compared with the variable $\mathrm{pH}$ of the gastrointestinal lumen. Although the contribution to metal binding and transport by the individual components in mucus has not yet been demonstrated, we have shown using snap-frozen sections that $\mathrm{Al}$ is avidly bound in situ by the intestinal mucus layer (Powell, 1994; Whitehead et al. 1995, 1996). There is clear delineation of the mucus, which stains well for $\mathrm{Al}$, and the mucosa, which lacks any detectable staining (Fig. 4), in keeping with the poor absorption (approximately $0.1 \%$ ) of the metal (Powell \& Thompson, 1993). In contrast, Quarterman (1987), using an elegant agar cast technique, was able to demonstrate both mucus uptake and subsequent mucosal transfer of the much better-absorbed element $\mathrm{Zn}$ (Fig. 5). These findings provide strong evidence for the assimilation of metal ions from the luminal milieu by the intestinal mucus layer, and suggest that those ions easily absorbed traverse the layer, whereas those poorly absorbed remain bound and are shed with the mucus back into the

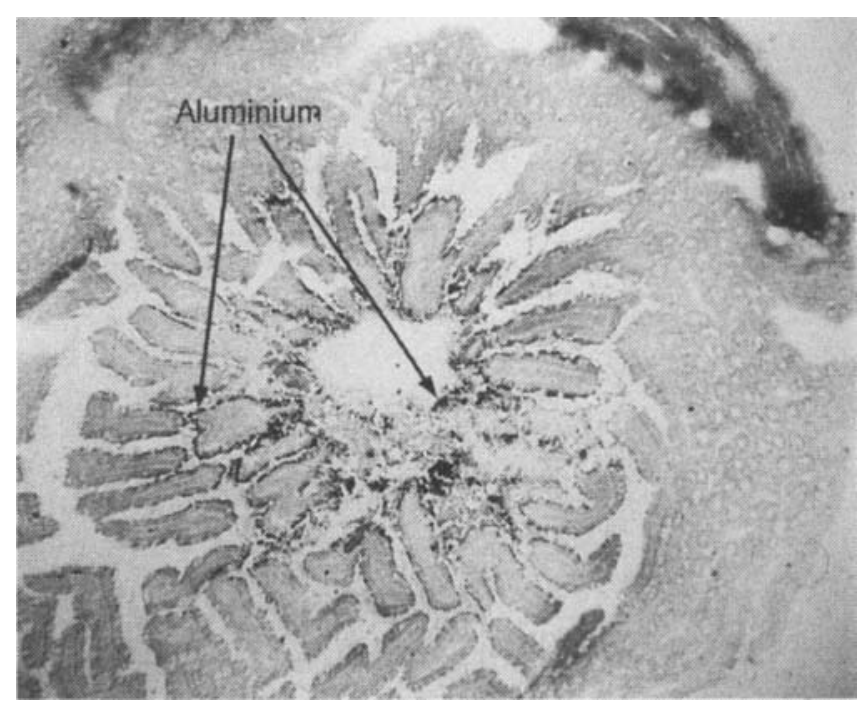

Fig. 4. Solochrome azurine stain showing association of aluminium with rat intestinal tissue following oral administration of aluminium sulfate in deionized water. Aluminium (shown as dark areas) is localized with the mucus layer at the villi surfaces and with soluble mucin in the lumen.

lumen, and excreted. Indeed, binding to mucus appears to follow the pattern $\mathrm{M}^{3+}>\mathrm{M}^{2+}>\mathrm{M}^{+}$(see p. 149), and for metal absorption the pattern is $\mathrm{M}^{+}>\mathrm{M}^{2+}>\mathrm{M}^{3+}$ (Whitehead et al. 1996). Thus, the mucus barrier may act initially as a 'coarse filter' in regulating metal uptake. As we have discussed elsewhere (Whitehead et al. 1996), the extent of luminal hydroxy-polymerization, rates of metal-ligand exchange, and mucosal transport systems (see p. 150) will all additionally act to control the degree of metal absorption. In addition, $\mathrm{pH}$ (and perhaps $\mathrm{pCa}$ or $\mathrm{pNa}$ ) gradients may play an important role in regulating uptake, and it is interesting to note that the $\mathrm{pH}$ at which there is least interaction of mucus and $\mathrm{Zn}$ (approximately $\mathrm{pH} 6.0$ ) appears to be the mammalian mucosal microclimate $\mathrm{pH}$ of the proximal small bowel (Lucas \& Blair, 1978). This may thereby facilitate cellular uptake of ions by dissociation of the metal-mucus complex and promotion of the final step, i.e. the metal-epithelial cell interaction.

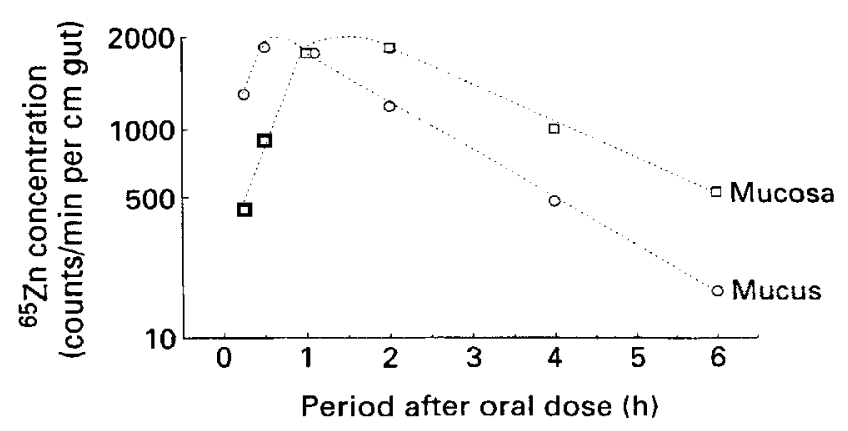

Fig. 5. Uptake of ${ }^{65} \mathrm{Zn}$ (counts/min per $\mathrm{cm}$ gut) into the mucus layer (O) and mucosa ( $\square$ ) of rats following an oral dose of zinc sulfate. (Data modified from Quarterman, 1987, with permission.) 


\section{Mucosal regulation}

Absorption from the mucus layer and into the intestinal mucosa may occur either through the enterocyte (transcellular) or between enterocyte junctions (paracellular; Powell et al. 1994). The latter route is inefficient (usually $<1 \%$ ) and likely, therefore, only to be important in the absorption of non-essential polyvalent metals $\left(\mathrm{M}^{>2+}\right.$, e.g. $\mathrm{Bi}$ and $\mathrm{Al}$ ) that lack a transport system. Efficiency of this route ("paracellular leakage') may be increased by the ingestion, or mucosal application of penetration enhancers. Such substances either chelate intercellular $\mathrm{Ca}^{2+}$ (e.g. citrate), since $\mathrm{Ca}^{2+}$ is important in normal maintenance of the tight junctional integrity, or undergo rapid enterocyte metabolism (e.g. glucose) causing cytoskeletal contraction and an increase in junctional space (Powell et al. 1994). However, for the absorption of most essential metals a transcellular route facilitated by a mucosal transport system is likely to operate. Until recently, direct evidence was lacking on the molecular mechanisms involved in metal ion uptake at the intestinal mucosa. Advances in molecular techniques have generated much new information, chiefly on the acquisition of $\mathrm{Fe}$ and $\mathrm{Zn}$, underlying their physiological importance, but the broad concepts are likely to be applicable to other essential elements such as $\mathrm{Cu}$ and $\mathrm{Mn}$. The following section outlines some of this newer information and speculates how it may be pieced together, rather than providing a comprehensive review.

It is well recognized that in the absence of genetic haemochromatosis body $\mathrm{Fe}$ stores influence inversely the efficiency of $\mathrm{Fe}$ absorption. However, there is a complex sequence of factors controlling this $\mathrm{Fe}$ homeostasis at the intestinal level that is quite different from the normal transferrin-associated $\mathrm{Fe}$ uptake seen in cells of other tissues. Three steps are considered in the uptake of metal ions by enterocytes. The first is transport through the luminal (apical) cell membrane, the second is handling within the enterocyte, and the third is transport through the antiluminal (basolateral) membrane into the circulation.

Arguably, transmembrane shuttles are not required for the passage of divalent ions across the intestinal mucosa, as facilitated transfer could be achieved through intracellular chelating agents providing the necessary gradient (Whitehead et al. 1996). However, recent findings strongly support the presence of transmembrane transporters. A transferrin-like protein (melanotransferrin) linked to a cellsurface glycosyl-phosphatidylinositol has been described in fetal porcine intestinal cells, but its role in adult mammals was not demonstrated, and further information is required to assess its role in neonatal Fe absorption (Danielsen \& Deurs, 1995). The transmembrane dimeric integrin complex with an $\alpha$ chain of $150 \mathrm{kDa}$ and $\beta$ chain of $90 \mathrm{kDa}$ has been strongly supported by Conrad and colleagues (Conrad et al. 1993b; Umbreit et al. 1998) for a role in apical $\mathrm{Fe}$ transportation. Typically, the $\alpha$ chain has several cationbinding sites often occupied by $\mathrm{Ca}$, but as discussed by Umbreit et al. (1998) integrins lack normal transport-protein properties. Integrins are transmembrane molecules and their extracellular domains function as adhesion sites for cell-cell or cell-matrix interactions, while their intracellular cytoplasmic tail provides linkage for intemal cytoskeletal proteins. Thus, it is proposed that these integrins are involved in the 'docking' of intracellular $\mathrm{Fe}$ carriers such as mobilferrin (see p. 151), facilitating the uptake of ions by enterocytes without themselves undertaking transport (Umbreit et al. 1998). Indeed, the actual transmembrane transport of Fe may involve a ferrireductase enzyme that has been demonstrated at the mucosal surface and uniquely reduces $\mathrm{Fe}^{3+}$ to $\mathrm{Fe}^{2+}$ (Riedal et al. 1995; Pountney et al. 1996). This would allow subsequent $\mathrm{Fe}$ absorption through a common divalent cation transporter, and protect against inadvertent uptake of the highly toxic $\mathrm{Al}^{3+}$ ion and other trivalent metal ions that do not have redox potential. A divalent cation transporter (divalent cation transporter 1) has recently been cloned that is expressed at high levels in enterocytes of the proximal small bowel and appears to have many transmembrane domains, making its expression at the cell surface likely (Gunshin et al. 1997). This protein shows significant homology with the natural resistance-associated macrophage protein family, and while it avidly binds $\mathrm{Fe}^{2+}$, it also has a broad substrate range of other divalent cations, including $\mathrm{Cu}^{2+}, \mathrm{Mn}^{2+}$ and $\mathrm{Zn}^{2+}$ (Gunshin et al. 1997). This binding of metal ions, which is a proton-coupled process, is favoured at the mildly acidic $\mathrm{pH}$ typically found in the micro-environment of the gastrointestinal mucus layer. As discussed previously, the $\mathrm{pH}$ gradient of the mucus layer may serve to de-couple metal-mucus interactions (Fig. 4) at the mucosal surface and promote the coupling of apical transporter and metal ion. Internalization of the metal ion (with or without its binding protein) has not been directly demonstrated, although findings with fetal melanotransferrin suggest this mechanism (Danielsen \& Deurs, 1995).

In some tissues such as the liver, Fe-responsive proteins appear integral to the regulation of cellular $\mathrm{Fe}$ concentrations acting as Fe sensors in the cell cytosol, but there is little evidence for an action of Fe-responsive proteins in intestinal epithelial cells (Chrichton \& Ward, 1998). Instead, the recently-identified $H F E$ gene (previously termed $H L A-H$ due to the similarity with the human leucocyte antigen family), that generally carries a point mutation in genetic haemochromatosis, may be involved in controlling Fe levels in the absorptive intestinal cells (Feder et al. 1996). This gene encodes for a protein (HFE; previously termed human leucocyte antigen $\mathrm{H}$ ) that is related to the major histocompatibility complex class I and, similarly, associates with $\beta_{2}$-microglobulin and is expressed at the cell surface (Feder et al. 1998). Thus, HFE has only a short cytoplasmic tail and a single membrane-spanning region that is inconsistent with a role as an ion transporter (Gunshin et al. 1997). More recent findings suggest that the role of HFE is in regulation of Fe transfer from epithelial cells to the circulation by regulated interaction with the basolateral transferrin receptors (Feder et al. 1998; Lebron et al. 1998; see p. 152).

Intracellular metal-binding proteins have been reported, most notably mobilferrin (Conrad et al. 1990; Conrad et al. 1990, 1994, 1996; Umbreit et al. 1998). Mobilferrin is a $56 \mathrm{kDa}$ intracellular protein that has been isolated from both rat and human small intestine and is homologous with the Ca-binding protein calreticulin (Conrad et al. 1993a). Interestingly, calreticulin has chaperone activity in the formation of major histocompatibility complex class I 
complexes (Umbreit et al. 1998), so perhaps it has similar activity for the putative Fe-regulating protein HFE (which is major histocompatibility complex class I-like). Mobilferrin binds metal ions such as $\mathrm{Ca}, \mathrm{Cu}$ and $\mathrm{Zn}$ with relatively high affinity, and is a particularly strong binder of $\mathrm{Fe}$ (Conrad et al. 1990). These interactions are acid-sensitive, again suggesting $\mathrm{pH}$ gradients as a means to associate and dissociate metal-mobilferrin complexes. As we have previously noted (Whitehead et al. 1996), it remains to be established if trace-metal-mobilferrin complexes are sufficiently stable in the presence of the relatively high levels of intracellular $\mathrm{Ca}$. Nonetheless, a number of papers from Conrad's group (Conrad et al. 1990, 1993a,b, 1994; Umbreit et al. 1996, 1998) point to a key role for this molecule, at least in intracellular Fe regulation. In fact this work goes further, suggesting that following acquisition of the $\mathrm{Fe}$, mobilferrin binds into a large protein complex termed 'paraferritin' containing solubilized integrin, mobilferrin, metal ion, $\beta_{2}$-microglobulin and 'unidentified polypeptides' (Umbreit et al. 1996, 1998). Since $\beta_{2-}$ microglobulin normally stabilizes major histocompatibility complex class I-peptide complexes (Song \& Harding, 1996), it may be that the major histocompatibility complex class I-like putative Fe-regulating protein HFE is also involved in this complex. Similarly, for $\mathrm{Fe}$, ferritin sequesters excessive levels of the metal, possibly providing a short-term depot of $\mathrm{Fe}$ before the cell is sloughed into the lumen, while preventing Fe-related free-radical damage to the cell, but a significant role in Fe transport has not been shown. Indeed, a number of molecules, such as metallothioneins, exist in the cell cytosol that are likely to be involved in the transient sequestering of absorbed metal ions, particularly when the influx of metal ions is high (Davis et al. 1998).

Finally, a basolateral transporter, such as transferrin for $\mathrm{Fe}$, appears to shuttle ions from the cell through the basolateral membrane to the circulation. A lack of mRNA for transferrin in the enterocyte suggests that there is no constitutive expression of the protein in intestinal cells (Chrichton \& Ward, 1998). However, basolateral transferrin receptors (there is normally no apical expression) may allow influx of transferrin and efflux of Fe-transferrin (Chrichton \& Ward, 1998). This flux of transferrin appears to be one major regulatory mechanism in $\mathrm{Fe}$ homeostasis, because in genetic haemochromatosis there is inefficient interaction of the transferrin receptor with the (abnormal) Fe-regulatory HFE protein (Feder et al. 1998) and hence upregulation of the receptor (Chrichton \& Ward, 1998). Similarly, for $\mathrm{Zn}$, a basolateral $\mathrm{Zn}$ transporter ( $\mathrm{Zn}$ transporter-1) partly regulates flux from intestinal cells (McMahon \& Cousins, 1998).

Hence, in summary, assimilation of metal ions in an available form is facilitated by the intestinal secretions, chiefly soluble mucus (mucin). Metal ions then bind and traverse the mucosally-adherent mucus layer with an efficiency $\mathrm{M}^{+}>\mathrm{M}^{2+}>\mathrm{M}^{3+}$. At the mucosa, $\mathrm{Fe}^{3+}$ is uniquely reduced to $\mathrm{Fe}^{2+}$. Divalent cations (including $\mathrm{Fe}^{2+}$ ) are transported by a membrane protein (such as divalent cation transporter 1) into the cell. Intracellular metal-binding molecules (such as mobilferrin) may be present at the intracellular side of the apical membrane, anchored to a transmembrane protein such as an integrin complex.
This mobilferrin would receive the metal ion from divalent cation transporter 1 and, with part of the integrin molecule, transport the metal to the cytosol for safe sequestration in a larger complex such as ferritin or 'paraferritin'. Finally, a systemic ion-binding protein such as transferrin may enter the antiluminal (basolateral) side of the cell for binding of the sequestered metal ion and delivery to the circulation. This would allow some external regulation, by the liver, of the release of $\mathrm{Fe}$ from the enterocytes to the circulation, perhaps determined by the extent of liver $\mathrm{Fe}$ stores. Regulatory proteins, such as HFE, may determine degree of ion transport from intestinal cells to the circulation. Gradients in $\mathrm{pH}$ and perhaps $\mathrm{pCa}$ or even $\mathrm{pNa}$ could allow the switching of ions between the different transporters throughout this mechanism.

\section{Acknowledgements}

J. J. P. is supported by a fellowship from the Medical Research Council. The authors are also grateful to Dr H. Ota and Professor T. Katsuyama (Shinshu University, Japan) for kind provision of Fig. 1, and similarly, Dr J. Quarterman (Aberdeen, Scotland) for Fig. 3. Dr M. E. Conrad and Gastroenterology kindly gave permission for reproduction of some data in Fig. 2. Data was also reproduced with the permission of Digestion (Figs. 2 and 5). Avril Rhodda and Miranda Lomer helped with preparation of the manuscript.

\section{References}

Bates GW (1973) Complex formation, polymerization, and autoreduction in the ferric fructose system. Bioinorganic Chemistry 2, 311-327.

Bates GW, Boyer J, Hegenauer JC \& Saltman P (1972) Facilitation of iron absorption by ferric fructose. American Journal of Clinical Nutrition 25, 983-986.

Champagne ET (1989) Low gastric hydrochloric acid secretion and mineral bioavailability. In Advances in Experimental Medicine and Biology, vol. 249, Mineral Absorption in the Monogastric GI Tract, pp. 173-184 [F Dintzis and J Laszlo, editors]. New York: Plenum Press.

Chrichton RR \& Ward RJ (1998) Iron Homeostasis. Basel, Switzerland: Marcel Dekker.

Conrad ME, Umbreit JN \& Moore EG (1991) A role for mucin in the absorption of inorganic iron and other metal cations: a study in rats. Gastroenterology 100, 129-136.

Conrad ME, Umbreit JN \& Moore EG (1993a) Rat duodenal ironbinding protein mobilferrin is a homologue of calreticulin. Gastroenterology 104, 1700-1704.

Conrad ME, Umbreit JN, Moore EG \& Heiman D (1996) Mobilferrin is an intermediate in iron transport between transferrin and haemoglobin in K562 cells. Journal of Clinical Investigation 98, 1449-1454.

Conrad ME, Umbreit JN, Moore EG, Peterson RDA \& Jones MB (1990) A newly identified iron binding protein in duodenal mucosa of rats: purification and characterization of mobilferrin. Journal of Biological Chemistry 265, 5273-5279.

Conrad ME, Umbreit JN, Moore EG, Uzel C \& Berry MR (1994) Alternate iron transport pathway: Mobilferrin and integrin in K562 cells. Journal of Biological Chemistry 269, 7169-7173.

Conrad ME, Umbreit JN, Peterson RDA, Moore EG \& Harper KP (1993b) Function of integrin in duodenal mucosal uptake of iron. Blood 81, 517-521. 
Crowther RS (1982) Cation induced changes in the biophysical properties of mucus glycoproteins. $\mathrm{PhD}$ Thesis, University of London.

Crowther RS \& Marriott C (1984) Counter-ion binding to mucus glycoproteins. Journal of Pharmacy and Pharmacology 36, 21-26.

Danielsen EM \& Deurs BV (1995) A transferrin-like GPI-linked iron-binding protein in detergent-insoluble noncaveolar microdomains at the apical surface of fetal intestinal epithelial cells. Joumal of Cell Biology 131, 939-950.

Davis PS, Multani JS, Cepeeneek CP \& Saltman P (1969) Isolation of gastroferrin from human gastric juice. Biochemical and Biophysical Research Communications 37, 532-537.

Davis SR, McMahon RJ \& Cousins RJ (1998) Metallothionein knockout and transgenic mice exhibit altered intestinal processing of zinc with uniform zinc-dependent zinc transporter1 expression. Journal of Nutrition 128, 825-831.

Feder JN, Gnirke A, Thomas W, Tsuchihashi Z, Ruddy DA, Basava A, Dormishian F, Domingo R Jr, Ellis MC, Fullan A, Hinton LM, Jones NL, Kimmel BE, Kronmal GS, Lauer P, Lee VK, Loeb DB, Mapa FA, McClelland E, Meyer NC, Mintier GA, Moeller N, Moore T, Morikang E, Prass CE, Quintana L, Starnes SM, Schatzman RC, Brunke KJ, Drayna DT, Risch NJ, Bacon BR \& Wolff RK (1996) A novel MHC class Ilike gene is mutated in patients with hereditary haemochromatosis. Nature Genetics 13, 399-408.

Feder JN, Penny DM, Irrinki A, Lee VK, Lebron JA, Watson N, Tsuchihashi Z, Sigal E, Bjorkman PJ \& Schatzman RC (1998) The hemochromatosis gene product complexes with the transferrin receptor and lowers its affinity for ligand binding. Proceedings of the National Academy of Sciences USA 95, 14721477.

Gunshin H, Mackenzie B, Berger UV, Gunshin Y, Romero MF, Boron WF, Nussberger S, Gollan JL \& Hediger MA (1997) Cloning and characterisation of a mammalian proton-coupled metal-ion transporter. Nature $388,482-488$.

Hunter AC, Allen A \& Garner A (1989) Studies on mucus biosynthesis in the gastrointestinal tract. In Symposia of the Society for Experimental Biology, no. 43, Mucus and Related Topics, pp. 27-36 [E Chantler and N Ratcliffe, editors]. Cambridge: Cambridge Society for Experimental Biology.

Lebron JA, Bennett MJ, Vaughn DE, Chirino AJ, Snow PM, Mintier GA, Feder JN \& Bjorkman PJ (1998) Crystal structure of the hemochromatosis protein HFE and characterization of its interaction with transferrin receptor. Cell 93, 111-123.

Lucas ML \& Blair JA (1978) The magnitude and distribution of the acid microclimate in proximal jejenum and its relation to luminal acidification. Proceedings of the Royal Society London A200, $27-41$.

McMahon RJ \& Cousins R (1998) Mammalian zinc transporters. Journal of Nutrition 128, 667-670.

Ota H \& Katsuyama T (1992) Alternating laminated array of two types of mucin in the human gastric surface mucous layer. Histochemical Journal 24, 86-92.
Pountney DJ, Raja KB, Bottwood MJ, Wrigglesworth JM \& Simpson RJ (1996) Mucosal surface ferricyanide reductase activity in mouse duodenum. Biometals 9, 15-20.

Powell JJ (1994) Aluminium in the gastrointestinal tract. PhD Thesis, United Medical and Dental Schools, University of London.

Powell JJ, Gartland KPR, Nicholson JK, Ainley CC \& Thompson RPH (1990) Bile, pancreatic juice and small bowel secretions contain endogenous metal binding ligands. Gut 31, A1197.

Powell JJ \& Thompson RPH (1993) The chemistry of aluminium in the gastrointestinal lumen and its uptake and absorption. Proceedings of the Nutrition Society 52, 241-253.

Powell JJ, Whitehead MW, Lee S \& Thompson RPH (1994) Mechanisms of gastrointestinal absorption: dietary minerals and the influence of beverage ingestion. Food Chemistry 51, 381-388.

Quarterman J (1987) Metal absorption and the intestinal mucus layer. Digestion 37, 1-9.

Rhodes JM (1989) Colonic mucus and mucosal glycoproteins: The key to colitis and cancer. Gut 30, 1660-1666.

Riedal HD, Remus AJ, Fitscher BA \& Stremmel W (1995) Characterization and partial purification of a ferrireductase from human duodenal microvillus membranes. Biochemical Journal 309, 745-748.

Rudzki Z, Baker RJ \& Deller DJ (1973) The iron-binding glycoprotein of human gastric juice: II nature of the interaction of the glycoprotein with iron. Digestion 8, 53-67.

Rudzki Z \& Deller DJ (1973) The iron binding glycoprotein of human gastric juice: I isolation and characterization. Digestion $\mathbf{8}$, $35-52$.

Shimizu T, Akamatsu T, Sugiyama A, Ota H \& Katsuyama T (1996) Helicobacter pylori and the surface mucous gel layer of the human stomach. Helicobacter 1, 207-217.

Song R \& Harding CV (1996) Roles of proteasomes, transporter for antigen presentation (TAP), and $\beta 2$-microglobulin in the processing of bacterial or particulate antigens via an alternative class I MHC processing pathway. Journal of Immunology 156, 4182-4190.

Stewart WK (1989) Aluminium toxicity in individuals with chronic renal disease. In Aluminium in Food and the Environment, pp. 7-19 [R Massey and D Taylor, editors]. London: Royal Society of Chemistry.

Umbreit JN, Conrad ME, Moore EG, Desai MP \& Turrens J (1996) Paraferritin: A protein complex with ferrireductase activity is associated with iron absorption in rats. Biochemistry 35, 64606469.

Umbreit JN, Conrad ME, Moore EG \& Latour LF (1998) Iron absorption and cellular transport: the mobilferrin/paraferritin paradigm. Seminars in Haematology 35, 13-26.

Whitehead MW, Farrar G, Christie G, Blair JA, Thompson RPH \& Powell JJ (1997) Mechanisms of aluminium absorption in the rat. American Joumal of Clinical Nutrition 65, 1446-1452.

Whitehead MW, Powell JJ \& Thompson RPH (1995) The gut mucus layer regulates metal absorption? Gut 36, A48.

Whitehead MW, Thompson RPH \& Powell JJ (1996) Regulation of metal absorption in the gastrointestinal tract. Gut 39, 625-628. 